\title{
An update on unilateral sporadic small vestibular schwannoma
}

\author{
*JaI Deep Thakur, M.D., ${ }^{1}$ Anirban Deep BanerJee, M.D., M.Ch., ${ }^{2}$ \\ Imad Saeed Khan, M.D., ${ }^{1}$ Ashish Sonig, M.D., M.S., M.Ch., ${ }^{1}$ Cedric D. Shorter, M.D., ${ }^{1}$ \\ Gale L. Gardner, M.D., ${ }^{3}$ Anil Nanda, M.D., M.P.H., ${ }^{1}$ ANd Bharat Guthikonda, M.D. ${ }^{1}$ \\ Departments of ${ }^{I}$ Neurosurgery and ${ }^{3}$ Otolaryngology, Louisiana State University Health Sciences \\ Center-Shreveport, Louisiana; and ${ }^{2}$ Department of Neurosurgery, Cleveland Clinic, Ohio
}

\begin{abstract}
Advances in neuroimaging have increased the detection rate of small vestibular schwannomas (VSs, maximum diameter $<25 \mathrm{~mm}$ ). Current management modalities include observation with serial imaging, stereotactic radiosurgery, and microsurgical resection. Selecting one approach over another invites speculation, and no standard management consensus has been established. Moreover, there is a distinct clinical heterogeneity among patients harboring small VSs, making standardization of management difficult. The aim of this article is to guide treating physicians toward the most plausible therapeutic option based on etiopathogenesis and the highest level of existing evidence specific to the different cohorts of hypothetical case scenarios.

Hypothetical cases were created to represent 5 commonly encountered scenarios involving patients with sporadic unilateral small VSs, and the literature was reviewed with a focus on small VS. The authors extrapolated from the data to the hypothetical case scenarios, and based on the level of evidence, they discuss the most suitable patientspecific treatment strategies. They conclude that observation and imaging, stereotactic radiosurgery, and microsurgery are all important components of the management strategy. Each has unique advantages and disadvantages best suited to certain clinical scenarios. The treatment of small VS should always be tailored to the clinical, personal, and social requirements of an individual patient, and a rigid treatment protocol is not practical.

(http://thejns.org/doi/abs/10.3171/2012.6.FOCUS12144)
\end{abstract}

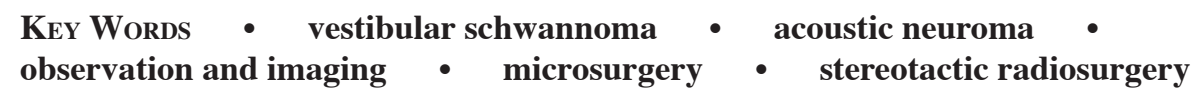

$\mathrm{T}$ IeChNOLOGICAL advances in neuroimaging have been responsible for changing the face of neurosurgery. This has certainly been true for VS, first described by Eduard Sandifort in the Netherlands in $1777 .{ }^{3}$ From what was considered a life-saving surgery (the finger extraction technique) done by Englishman Sir Charles Balance in $1894,{ }^{8} \mathrm{VS}$ treatment has evolved toward a more conservative management paradigm.

The common denominator for the evolution of VS treatment has been the focus on patients' quality of life. ${ }^{11}$ In the 1990s, achieving tumor control while preserving facial and cochlear nerve function were the ideal goals of surgery. The management of VS has developed further over the past decade, with importance being given to

Abbreviations used in this paper: $\mathrm{AAO}-\mathrm{HNS}=$ American Academy of Otolaryngology-Head and Neck Surgery; CPA = cerebellopontine angle; DPOAE = distortion products of otoacoustic emissions; GKS = Gamma Knife surgery; GRC = Gardner-Robertson Class; PTA = pure-tone average; SDS $=$ speech discrimination score; SRS = stereotactic radiosurgery; VS = vestibular schwannoma.

* Drs Thakur and Banerjee contributed equally to this work. postoperative quality of life. ${ }^{18,21,61,84,111}$ This is even more pertinent to patients with small tumors $(<25 \mathrm{~mm})$ or with minimal hearing deficits. ${ }^{21,61,111}$ Currently, the treatment options for managing small VS include conservative observation and serial imaging ("wait and scan"), stereotactic radiosurgery and microsurgery.

Formulating the best treatment strategy in patients with small tumors rests on the ability of the physician to understand specific patient and tumor characteristics and to be able to tailor the treatment options to the individual. The variability in the literature with respect to optimal treatment strategies for small VSs makes it even more challenging for the physician to formulate the most suitable plan. The main goal of this review is to outline the most suitable therapeutic option for different cohorts using hypothetical case scenarios and the highest level of evidence available. We list 5 hypothetical clinical situations and extrapolate from the reviewed literature pertinent to each clinical setting. Additionally, we discuss the proposed possible mechanisms of hearing loss in patients with small VSs. 


\section{What Actually Creates the Treatment Dilemma?}

Seth I. Rosenberg started his article on the natural history of acoustic neuroma ${ }^{86}$ by quoting from the 1904 article by Fraenkel et al.:.31 "An estimation of the size and character of the growth is nearly always a mere matter of speculation, based on tumor statistics, the rapidity of the clinical course, or associated constitutional conditions." Apart from improvements in estimating tumor location and size, this statement holds true even after 100 years of scientific progress. One of the challenges a physician still has to overcome is that of making a therapeutic decision when a patient with a small VS comes to the clinic with a normal or serviceable hearing level. The parameters that are considered essential for planning the treatment strategy are listed in Table 1.

The factors that make the final decision a daunting task include variability in the data on the natural history of $\mathrm{VS},{ }^{68,86,118}$ mechanism of hearing loss, ${ }^{27,37,57,81,99}$ and treatment-specific hearing and facial function preservation rates..$^{96,98,101}$ These inconsistencies are a major hindrance to the practice of evidence-based medicine. Meta-analyses of pooled data are fraught with considerable assumptions to simplify the nonuniform existent data and achieve statistical power and significance, which can greatly impact their conclusions..$^{100,101,111,115}$ These studies should thus be interpreted with caution.

The aim of the current review is not to address statistical "treatment-specific analysis," but rather highlight "case-specific" requirements and extrapolate from the literature in a simplified way for the treating physician.

\section{Mechanism of Hearing Loss in VS}

Considering the variability in the data regarding

TABLE 1: Essential parameters to be kept in mind while considering treatment options for small VS*

\begin{tabular}{l}
\hline \multicolumn{1}{c}{ Parameter } \\
\hline pt age, occupation, SES \\
tumor location \\
status of hearing; PTA \& SDS \\
status of CN V and VII function \\
tumor consistency \\
solid \\
cystic \\
mixed \\
tumor characteristics \\
calcification \\
microhemorrhages \\
fibrosis \\
necrosis \\
any comorbidities \\
expected impact of the treatment on QALYS \\
pt's personal preference
\end{tabular}

* $\mathrm{CN}=$ cranial nerve; $\mathrm{pt}=$ patient; $\mathrm{QALY}=$ quality-adjusted life year; SES = socioeconomic status. the natural history of VS and the difficulty in predicting hearing outcomes in individual cases, we sought to briefly review the proposed mechanism for hearing loss in VS (Fig. 1).

In general, there are 4 patterns of hearing loss: ${ }^{21,27,37,38 \text {, }}$ $51,57,71,72,81,991$ ) hearing deterioration in "growing" tumors, 2) hearing deterioration in "nongrowing" tumors, 3 ) early hearing loss, and 4) sudden hearing loss regardless of tumor growth.

Vestibular schwannomas are histologically benign, slow-growing tumors that originate from the Schwann cells of the inferior vestibular nerve in most cases. ${ }^{44}$ The location of the tumor's origin is described as the neurilemmal-neuroglial junction (Obersteiner-Redlich zone) within the internal auditory canal. ${ }^{48,67}$ Considering the origin of the tumor, the most obvious hypothesis for hearing loss is the mechanical and/or neurotoxic effect that a growing tumor might have on its neighboring neurovascu-

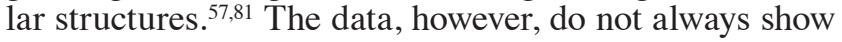
a linear correlation between the rate of tumor growth and deterioration of hearing. . $8,39,82,96,104^{2}$

\section{Hearing Loss in Patients with Growing Tumors}

The "mechanical effect" is thought to involve compression or stretching of the cochlear nerve (conduction block) or compromise of the vascular supply to the cochlea (through occlusion or spasm of the labyrinthine artery). ${ }^{81}$ This compromise of the vascular supply can be a result of an increase in intracanalicular pressure or due to direct compression caused by the laterally invading tumor., ${ }^{7}$ Compression of labyrinthine vessels has been shown to cause degeneration in the organ of Corti and the spiral ganglion (cochlear dysfunction). ${ }^{22,37,43,71}$ Of note, the progression of hearing loss in VS is most often gradual, 39,96 although sudden deterioration is also possible. ${ }^{32,65}$

\section{Hearing Loss in Patients with Nongrowing Tumors}

Another subset of VS patients develop hearing loss despite the lack of tumor growth on imaging..$^{38,75}$ Obviously, the mechanical effect theory fails to explain this category of hearing loss. In these patients, neurotoxic injury, caused either by alterations in the biochemical properties of the inner ear fluid or through accumulation of tumor toxic metabolites, may be responsible for hearing loss. The perilymphatic space and endolymphatic space in the inner ear of patients with VS often stain positive for eosinophilic proteinaceous deposits. ${ }^{26}$ The perilymphatic protein levels are reported to be 5-15 times higher than the levels found in the ears of healthy individuals..$^{93}$ This rich perilymphatic protein is believed to represent either a by-product of upregulated genetic activity in the VS ${ }^{109}$ or simply accumulation of serum proteins by the process of transudation. ${ }^{93}$ The correlation between increased proteinaceous material and cochlear dysfunction is still not clear.

\section{Early Hearing Loss}

Efferent olivocochlear bundle dysfunction and alteration in biochemical properties of the inner ear fluid seem to be the most plausible causes of early hearing loss in VS patients. Gouveris et al. ${ }^{37}$ compared DPOAE am- 


\section{Case-specific update on small VS}

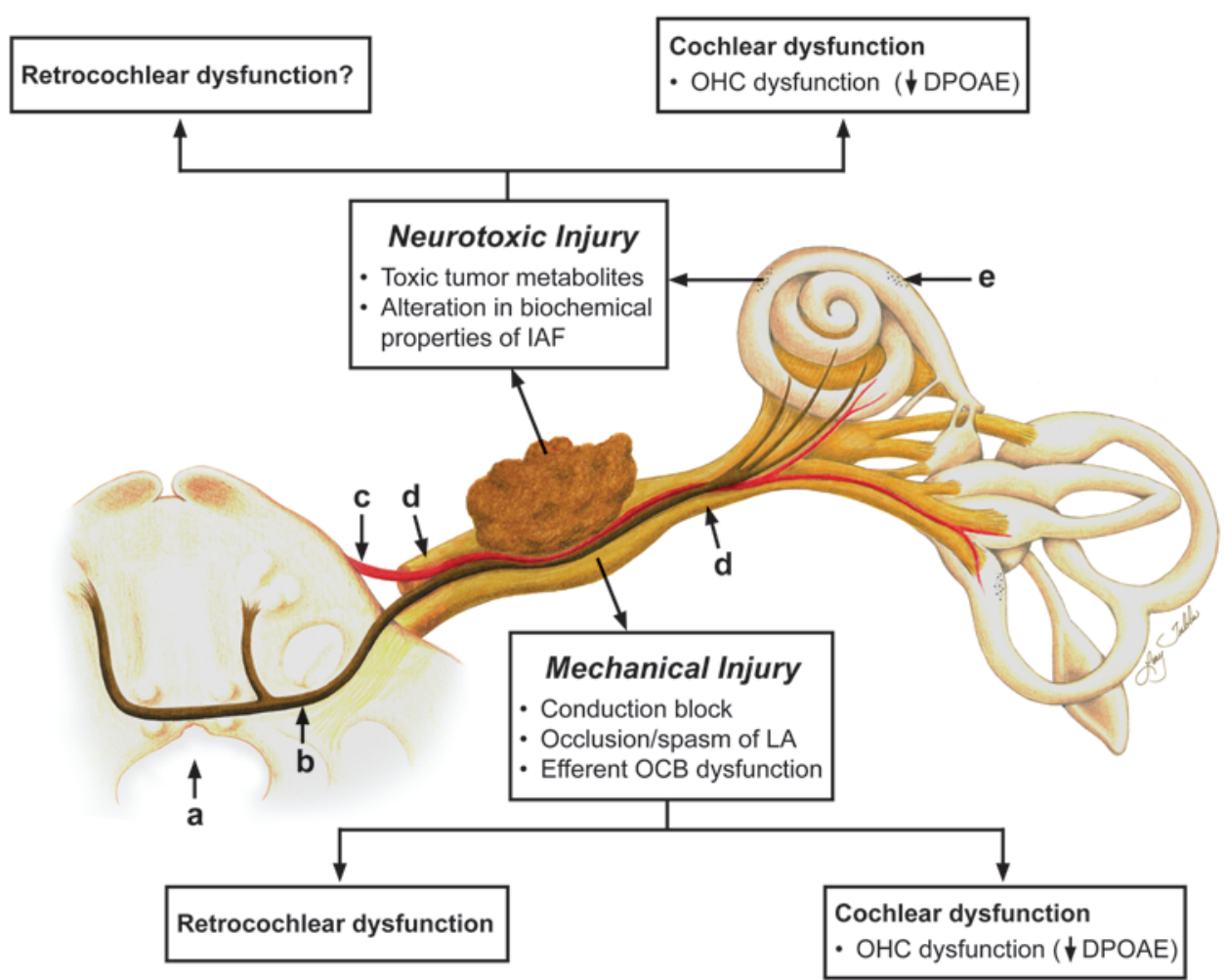

FIG. 1. A schematic showing the possible mechanism of hearing loss in a small VS. $a=$ fourth ventricle; $b=$ efferent olivocochlear tract; $c=$ labyrinthine artery $(L A) ; d=$ vestibulocochlear nerve; $e=$ proteinaceous deposits in the inner ear fluid due to tumor metabolism; IAF = inner ear fluid; $\mathrm{OCB}=$ olivocochlear bundle; $\mathrm{OHC}=$ outer hair cells.

plitudes between VS patients with normal, symmetrical hearing and VS patients with mild hearing loss. They reported that the early hearing loss in patients with VS was cochlear in origin, suggested by a consistent finding of decreased DPOAE amplitudes, indicating dysfunction of the outer hair cells. Although the authors did not provide the mean tumor size in their population, the concept of early hearing loss as cochlear in origin was striking. The possibility that a small intracanalicular tumor will impede cochlear blood flow to the level of causing outer hair cell dysfunction seems less likely. On the contrary, the proximity of the passing unmyelinated efferent olivocochlear tracts to the vestibular nerve suggests the etiology to be efferent auditory system dysfunction. ${ }^{81}$ The efferent olivocochlear bundle comprises medial fibers that innervate the outer hair cells and lateral fibers that synapse with the dendrites of the inner hair cells. The functions assigned to the efferent system of the ear include noise protection, improvement of signal-to-noise ratio, selective attention, adaptation, and frequency selectivity (through regulation of the micromechanical properties of outer hair cells). ${ }^{20}$ Additionally, functionality in the 3D auditory world-localization of sound and speech restorationis affected in efferent olivocochlear bundle dysfunction. ${ }^{20}$

Animal studies suggest a hearing loss of up to $60 \mathrm{~dB}$ related to efferent auditory dysfunction. ${ }^{73}$ Pennings et al..$^{75}$ followed 47 patients with purely intracanalicular tumors prospectively, without any intervention. At baseline, 12 patients already had PTA greater than $50 \mathrm{~dB}$. This suggests that efferent auditory dysfunction alone may not be responsible for early hearing loss and that alteration in the biochemical properties of the inner ear fluid might also play a role in the initial stages. Recently, van de Langenberg et al. ${ }^{104}$ reported that in patients undergoing serial imaging, there was significantly greater deterioration of PTA over time in the ears in which labyrinthine signal hypointensity was seen on T2-weighted MR images than in those that showed a more isointense intense labyrinthine signal ${ }^{104}(\mathrm{p}=0.01)$. Although nothing in the data suggested an explanation for this finding, the authors hypothesized that biochemical changes, including highly proteinaceous deposits and vascular compromise, might be the reason for the hypointensity.

\section{Sudden Hearing Loss}

Sudden hearing loss is also noted in some VS patients with documented rates between $3 \%$ and $23 \% .{ }^{88}$ The internal auditory artery or the labyrinthine artery (end artery) travels within the internal auditory canal, and it may be possible that vascular insult to it can result in sudden hearing loss. ${ }^{11,60}$ However, if only vascular insult was the cause, one would also expect to see vestibular symptoms and cochlear hearing loss, which is not always the case. Further, due to the anatomical distribution of the blood supply to the cochlea, vascular compromise should result in low-frequency hearing loss in these patients, whereas mostly higher-frequency loss is reported in such cases. ${ }^{51,52}$ Tumor characteristics, including accelerated tumor growth and an increased number of intratumoral hemorrhages, are thought to cause sudden hearing loss through 
nerve compression and rapid accumulation of biochemical toxins. ${ }^{99}$ A higher incidence of high- to mid-frequency hearing loss correlates well with the nerve compression theory, ${ }^{32}$ but otoacoustic emissions in such patients do not reflect purely retrocochlear hearing loss ${ }^{71}$ and suggest that both cochlear and retrocochlear components contribute to sudden hearing loss in such patients.

To summarize, it would be reasonable to state that the exact mechanism of hearing loss in VS patients is likely to be multifactorial. Better understanding of the possible etiologies of hearing loss will help in guiding VS treatment choices, not only on the basis of tumor size and location, but also based on the intricate patterns of inner ear functioning in VS patients at the time of presentation.

In the section below, we present 5 distinct case scenarios and review the literature that is most applicable to formulating a management plan for each hypothetical patient.

\section{Hypothetical Case Scenarios and Review of the Literature}

\section{Hypothetical Case 1}

This patient is a 40-year-old man with a small VS (maximum diameter $<25 \mathrm{~mm}$ ) that was discovered incidentally. The results of his audiometrical examination are within normal limits. Hearing preservation is his primary concern, as he works for a local music band and needs to have normal hearing to be successful. He inquires about the best option(s) for preserving his intact hearing status.

Advancements in neuroimaging have increased the rate of incidental detection of VS. In a recent Rotterdambased population study, the most common brain lesions discovered incidentally by MRI were asymptomatic brain infarcts, followed by cerebral aneurysms and primary benign tumors. ${ }^{105}$ The authors of the study reported the incidence of asymptomatic VS to be 1 in 500 individuals. A recent study of the Surveillance Epidemiology and End Results (SEER) US database identified the incidence rate of VS to be 1.1 per 100,000 , with the mean age of detection being 53.1 years and the majority of lesions (84\%) occurring in the Caucasian population. ${ }^{34}$

Tumors That Will Grow if Left to Observation. To address the patient's concern about the chances of hearing preservation, knowledge about the chances of the tumor showing growth and the probable growth rate are important. Combining the results of 6 previous meta-analyses shows that tumor growth occurred in $29 \%$ to $54 \%$ of patients (mean 44.6\%). ${ }^{4,9,89,95,101,113,118}$ A major drawback in the application of these results is that the mean follow-up time in these studies was only 3 years. A literature review of mostly Level 3 evidence yields impressive variability in growth rates (range 18\%-73\%). ${ }^{68}$ There are very few prospective studies that report tumor growth in the patients followed with observation. Régis et al. ${ }^{83}$ reported tumor growth in $77 \%$ of their patients (mean follow-up 5.3 years); Hajioff et al., ${ }^{39}$ in their 10 -year follow-up prospective study (median duration of follow-up 121 months), reported tumor growth in $78 \%$ of patients $(<1 \mathrm{~mm} /$ year in $38 \%$ and $>1$ $\mathrm{mm} /$ year in $40 \%$ ); and Stangerup et al. ${ }^{96}$ found that only $17 \%$ of intrameatal tumors became extrameatal and that only $28.9 \%$ of extrameatal tumors showed growth (mean follow-up 3.6 years). It is difficult to develop a scientific rationale that would explain this variation. Régis et al. ${ }^{83}$ pointed out that the definition of tumor growth was relatively personal. For example, Stangerup et al. considered a change in any tumor from intrameatal to extrameatal to be tumor growth, whereas Hajioff et al. defined significant growth as growth of more than $1 \mathrm{~mm} /$ year.

Tumor Growth Rates in Major Series. The inability to predict consistently whether a tumor will grow makes predicting the growth rate even more problematic. Tumor growth rate is a parameter about which there is general agreement with respect to treatment strategy decisions. A patient who has a tumor growth rate of more than 2-2.5 mm/year is at a significantly higher risk of hearing loss than a patient with less than $2.5 \mathrm{~mm}$ growth per year. ${ }^{38,39,75,101}$ This obviously does not account for patients who develop hearing loss without any significant tumor growth (as described earlier in this paper).

Recently, Sughrue et al., ${ }^{101}$ in their systematic review of 34 published studies that included 982 patients (Level 3 evidence), found that in $75.32 \%$ of the patients tumor growth was greater than $2.5 \mathrm{~mm} /$ year, and the mean tumor growth was $2.9 \mathrm{~mm} /$ year. In contrast, a prospective study by the same group showed a growth rate of less than $2.5 \mathrm{~mm} /$ year in $83 \%$ of patients. ${ }^{98}$ The authors of another recent prospective study documented the mean tumor growth in their population to be $2.1 \mathrm{~mm} /$ year. ${ }^{83}$ A 2005 systematic review by Yoshimoto ${ }^{118}$ included 4 prospective studies in which only $29 \%$ of tumors showed growth. There is a striking difference between the growth rates documented by older meta-analyses and the $2.9 \mathrm{~mm} /$ year reported by Sughrue et al. in their 2010 review. ${ }^{101}$ Mean tumor growth rates of $1.8,1.9,1.9,1.2$, and 2 (mm/year) were reported in the meta-analyses published in $1998,{ }^{89}$ $2003,{ }^{113} 2005,{ }^{95} 2005,{ }^{118}$ and $2006,{ }^{9}$ respectively.

Although there is variation in the literature, the results of prospective studies could be interpreted as suggesting that tumor growth is likely to be less than 2-2.5 $\mathrm{mm} /$ year in the majority of patients. Table 2 lists various factors that may have prognostic implications for VS growth patterns. ${ }^{2,5,13,28,39,41,59,62,68,101,104}$ But there is clearly a need for long-term prospective data documenting annual trends in tumor growth rates.

Hearing Preservation in Wait-and-Scan Group. The most recent meta-analysis, that of Sughrue et al. (2010), ${ }^{101}$ reviewed the literature on the natural history of untreated sporadic VS (tumor size $<25 \mathrm{~mm}$ ). In 982 patients, the overall hearing preservation rate was $54 \%$, with follow-

TABLE 2: Factors that may predict VS growth patterns

\begin{tabular}{l}
\hline \multicolumn{1}{c}{ Predictors } \\
\hline significant growth $(>2 \mathrm{~mm} / \mathrm{yr})$ \\
extension into the CPA \\
diameter $>20 \mathrm{~mm}$ \\
sudden onset or short duration of sensory hearing loss \\
tinnitus, unsteadiness, \& vertigo at presentation \\
\hline
\end{tabular}


up ranging from 26 to 52 months. Meta-analyses in the past have documented hearing preservation in 49\%-63\% of patients with a mean follow-up of approximately 3 years. ${ }^{9,89,94,101,113,118}$ Sughrue et al. found that the hearing preservation rate was significantly higher for the group of patients demonstrating a tumor growth rate of $2.5 \mathrm{~mm} /$ year or less. Interestingly, the overall mean growth rate among 982 patients included in their meta-analysis was $2.9 \pm 1.2 \mathrm{~mm} /$ year. It is worth mentioning a common finding among the majority of the wait-and-scan group studies, which is deterioration of PTA and SDS over years in almost all the patients presenting initially with some degree of hearing loss.$^{39,75}$ Régis et al. ${ }^{83}$ in their cohort of 40 patients followed up for a mean of 43.8 months, reported useful hearing preservation rates of $75 \%, 52 \%$, and $41 \%$ at 3,4 , and 5 years, respectively.

A prospective study from the University of California, San Francisco group (Sughrue et al. 2011 ${ }^{98}$ ) calculated the estimated time to hearing loss among 3 groups of patients - those with intracanalicular tumors, those with 0.1-1 cm extension into the CPA, and those with more than $1 \mathrm{~cm}$ extension into the CPA cistern. The estimated median time to hearing loss in these 3 groups was 11.6, 10.3 , and 9.3 years, respectively. Further, the authors noted that the median time of hearing loss in patients with a tumor growth rate of more than $2.5 \mathrm{~mm} /$ year was 7 years as compared with 14.8 years in those with growth of less than $2.5 \mathrm{~mm}$ /year. Hajioff et al. ${ }^{39}$ followed a cohort of 72 patients prospectively for a median of 121 months (range 80-271 months); $49 \%$ of the patients were advanced in age and $43 \%$ made a personal choice for observation. The authors noted that the patients' hearing deteriorated substantially even in cases of nongrowing tumors. The mean deterioration in PTA at $0.5,1,2$, and $3 \mathrm{kHz}$ was $36 \mathrm{~dB}$, and the SDS deteriorated by a mean of $40 \%$. The overall failure rate in their cohort was $40 \%$, with three-fourths of the failures occurring during the first half of the study.

Another recent noncomparative prospective study followed 186 consecutive patients (median follow-up 43 months), all of which were initially allocated to conservative treatment..$^{13}$ At the last follow-up, $40 \%$ of the patients required either radiosurgery or microsurgery and the median time to treatment was given as 26 months (SD 17.4 months). Serviceable hearing at 1-3 years and/or beyond 3 years was significantly decreased as compared with baseline hearing status.

Recently, Stangerup et al. ${ }^{97}$ reported the results of their 932 VS cases managed with observation; 102 patients $(11 \%)$ were observed for over 10 years and hearing preservation was seen in $46 \%$. In this study, the author found that patients with $100 \%$ SDS at diagnosis have a $75 \%$ chance of maintaining good hearing even after 10 years of observation, which was in agreement with various other studies.

Some reproducible conclusions (Table 3 ) made from a review of literature regarding observation ${ }^{75,96,101,104}$ include the following: 1) Patients with an SDS of $100 \%$ at diagnosis have higher chances of long-term hearing preservation. 2) Hearing preservation rates are markedly higher for the patients with tumor growth of less than 2-2.5 mm/ year. 3) Most tumors demonstrate growth within the first
TABLE 3: Factors predicting hearing outcomes in the observation and imaging group*

\begin{tabular}{l}
\hline \multicolumn{1}{c}{ Category \& Factor } \\
\hline factors predicting hearing loss \\
signal hypointensity in the affected labyrinth on T2-weighted MR \\
images \\
established hearing loss at initial presentation \\
tumor growth $>2.5 \mathrm{~mm} / \mathrm{yr}$ \\
factors predicting better hearing outcomes \\
WRS Class 0 or 1 at initial presentation \\
initial hearing level up to $10 \mathrm{~dB}$ HL at $4000 \mathrm{~Hz}$ \\
tumor growth $<2.5 \mathrm{~mm} / \mathrm{yr}$ \\
\hline$* \mathrm{HL}=$ hearing loss; WRS $=$ word recognition score.
\end{tabular}

5 years of diagnosis. 4) Regardless of tumor growth, hearing deterioration is bound to happen without intervention.

Based on the current literature, a strategy of observation and serial imaging may be continued in a young or middle-aged patient who has normal findings on audiometric examination and a VS that has not demonstrated significant growth. However, if the tumor starts growing, the chance of losing serviceable hearing will increase. Is there a role for early intervention (SRS/MS) in these patients? The chances of hearing preservation in patients treated by means of SRS or microsurgery will be discussed subsequently under Hypothetical Case 2; this discussion will also clarify the role of early intervention in Hypothetical Case 1.

It is also worthwhile to mention that even in some academic centers of excellence, where the patients are sent constant reminders for follow-up, the percentage of patients lost to follow-up can be substantial. If we consider health care centers where following up is at the discretion of the patient only and regular follow-up is hindered by numerous factors including socioeconomic status and health insurance issues, it is quite worrisome to imagine the dropout rates from the observation subset of patients.

\section{Hypothetical Case 2}

This patient is a 40-year-old woman with a small VS $(<25 \mathrm{~mm})$ and mild hearing loss (serviceable hearing). Understandably, the patient wants to prevent any further hearing deterioration. She is open to any treatment modality that may stabilize her mild hearing loss or even improve her hearing.

The presence of any symptoms at presentation reflects some significant ongoing biological activity in the tumor causing anatomical and physiological compromise. The possible mechanisms ${ }^{57,81}$ through which functional compromise can take place include 1) mechanical compression, 2) neurotoxic effects mediated through either toxic by-products of tumor metabolism or alteration in the inner ear fluid biochemistry, and 3) efferent pathway dysfunction. As previously discussed, there is significant heterogeneity in the data with respect to tumor growth in the absence of treatment; given this heterogeneity, observation and serial imaging is not a reasonable strategy for 
patients who present with some hearing loss but want to preserve a serviceable hearing level.

In contrast to the data on growth of untreated tumors, the data available in the literature addressing tumor growth control following SRS demonstrate impressive consistency. The tumor control rate after SRS among the meta-analytical studies ${ }^{9,47,91,108,113-116}$ in the last decade (regardless of tumor size) range from $91 \%$ to $94.7 \%$, with a mean of $93.4 \%$. Even though microsurgical removal of small VSs is the most effective means of long-term tumor volume reduction, the associated morbidities and lesser rates of hearing preservation, make it a less popular treatment strategy among physicians and patients (details to be discussed later). Of note, stabilizing the tumor through SRS does not preclude the chances of hearing deterioration and there is a subset of patients who experience sudden hearing loss after SRS. ${ }^{30,40,49,56,69,78,84,85,103,106,112}$ Nevertheless, the chance of this phenomenon is less in patients in whom the median tumor dose does not exceed 13 Gy. ${ }^{19,45,52,58,69,108}$

\section{Radiobiology of VS}

Ionizing radiation induces cell cycle arrest, necrotic cell death, or both in VS. ${ }^{117}$ The higher the number of tumor cells in the proliferative phase, the more radiosensitive is the tumor. ${ }^{53,54}$ Ionizing radiation arrests the tumor cells in the proliferative phase such that the cell cycle checkpoint signaling (activated by DNA damaging agents) prevents the replication of damaged DNA as well as segregation of aberrant chromosomes, thus achieving tumor control. ${ }^{117}$ The radiation also induces double-strand DNA breaks, which leads to apoptosis. ${ }^{52}$ In addition to a low proliferative index, another factor causing radioresistance is tumor hypoxia. Rapidly growing tumors will be more hypoxic due to inadequate angiogenesis and therefore may be more radio-resistant. ${ }^{6}$

Lee et al. ${ }^{53}$ found that recurrent VSs removed through microsurgery, which were previously treated by Gamma Knife surgery, had lower a proliferation rate than those treated primarily by microsurgery $(\mathrm{p}=0.03)$. This suggests that radiosurgery might be able to induce apoptosis in the cells with a high proliferative index and leave behind those with a low proliferative index. Surgical removal alone, especially subtotal resection, might leave behind a mixed population of tumor cells, and subsequently the cells with a high proliferative index might continue to grow.

On occasions, VSs may show a transient increase in size following SRS. ${ }^{64,77}$ This phenomenon is reported to occur in $17 \%-74 \%$ of patients undergoing SRS. It may be attributed secondary to radiation-induced tumor necrosis, chronic intratumoral bleeding, or biological response to ionizing radiation. A higher radiation dose has also been described as a possible risk factor for expansion. ${ }^{43,66,80} \mathrm{Ad}-$ ditionally, the growth may also be associated with transient facial spasm and trigeminal nerve dysfunction. ${ }^{64}$ This transient expansion is most evident within the 1st year of treatment, and in most cases the tumor volume eventually becomes significantly less than before treatment. Rarely, continued growth after transient expansion is noted. If the growth is persistent and becomes symptomatic, further SRS or microsurgery is usually recommended.
Chances of Hearing Preservation After SRS. Yang et al., ${ }^{114}$ in their 2010 review, quantified data from 45 published studies to investigate hearing preservation rates after SRS. The overall hearing preservation rate (AAO-HNS Class 1 or 2, GRC 1 or 2) was reported to be $51 \%$ (mean follow-up $44.4 \pm 32$ months [SD]). This outcome appeared to be dose dependent. The studies that used a radiation dose of $13 \mathrm{~Gy}$ or less had a preservation rate of $60.5 \%$, which was significantly higher than the studies in which the dose was larger than $13 \mathrm{~Gy}$ (50.4\%). Some recent contemporary retrospective studies ${ }^{30,52,56,103}$ using mean tumor margin doses of less than 13 Gy have reported long-term hearing preservation rate ranging from $68 \%$ to $93.3 \%$. Details of hearing outcome in the prospective studies are shown in Table 4 . The hearing preservation rates in these studies range from $63 \%$ to $93 \%$ for patients with VSs smaller than $3 \mathrm{~cm}$ in maximum diameter. Additionally Niranjan et al. ${ }^{69}$ followed 96 patients with intracanalicular tumors prospectively and found that serviceable hearing in $77.5 \%$ of the patients with AAO-HNS Grade 1 hearing preoperatively and in $64.5 \%$ in those with Grade 2 preoperatively (mean follow-up 42 months). Facial and trigeminal nerve function was preserved in $100 \%$ of the patients.

In 2010, Régis et al. ${ }^{83}$ published the results of a prospective comparative study on intracanalicular VS, in which they compared patients treated with GKS with the wait-and-scan group. In the 34 patients treated by GKS, the useful hearing preservation rates at 3, 4, and 5 years were $77 \%, 70 \%$, and $64 \%$ in comparison with $75 \%, 52 \%$ and $41 \%$ in the wait-and-scan group at the same followup points. Also, in that study the chance of maintaining functional hearing and avoiding further intervention was $79 \%$ at 2 years' follow-up and $60 \%$ at 5 years' follow-up in the GKS group compared with $43 \%$ and $14 \%$ in the wait-and-scan group.

Hearing Loss After SRS. Gamma Knife surgery for VS has occasionally been shown to cause hearing loss, especially within the first 12 months. Wackym et al. ${ }^{106}$ prospectively evaluated 59 patients treated with SRS (mean follow-up 63.76 months). They found that limiting the cochlear dose of radiation to less than 4 Gy can significantly decrease the incidence of hearing loss. They noted a distinct pattern of hearing loss in their cohort of patients, similar to what was reported earlier by Lasak et al. ${ }^{52}$ It was consistent with a type of hearing loss resulting from radiation-induced injury to stria vascularis, characterized by a strial presbyacusis-like pattern with hearing loss across all frequencies and relative preservation of speech discrimination ability. Other proposed mechanisms of hearing loss after SRS are damage to spiral ganglion neurons inside the modiolus and ischemic insult to the primary afferent and efferent nerve fibers within the internal auditory canal..$^{52}$ Therefore, modulation of the radiation dose to the cochlea below $4 \mathrm{~Gy}$ and appropriate shielding techniques employed for protection of the cochlea are reasonable options that may help in decreasing the incidence of hearing loss after SRS.

Hearing Outcomes After Microsurgery. Recently, Sughrue et al. ${ }^{100}$ performed a systematic review to highlight the hearing preservation rates after microsurgical re- 


\section{Case-specific update on small VS}

TABLE 4: Summary of results of prospective studies comparing microsurgery and radiosurgery in small VSs $(<3 \mathrm{~cm})^{*}$

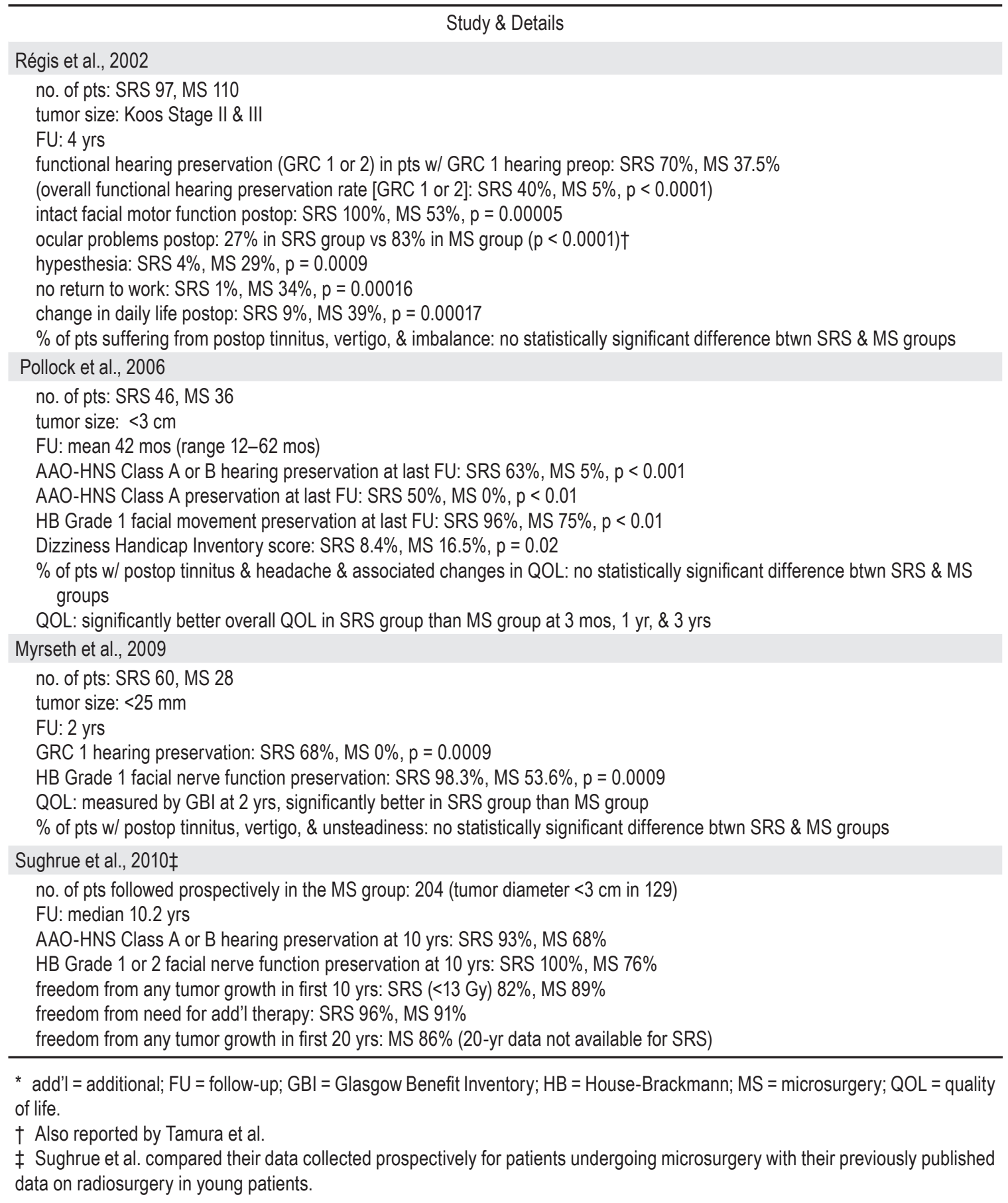

section of VS. In the selected 49 published articles, which included 998 patients, an overall hearing preservation rate of $52 \%$ was reported. Interestingly, the breakdown of the results according to tumor diameter revealed hearing preservation in the different subgroups as follows: $64 \%$ in patients with tumors less than $1 \mathrm{~cm}$ in diameter; $61 \%$ in those with tumors $1-1.5 \mathrm{~cm}$ in diameter; $32 \%$ in those with tumors $1.5-2 \mathrm{~cm}$ in diameter; and $37 \%$ in those with tumors $2-2.5 \mathrm{~cm}$ in diameter $(\mathrm{p}<0.0001)$. A very significant drop in hearing preservation was observed when the tumor di- ameter increased beyond $1.5 \mathrm{~cm}$. Comparison of the largest systematic reviews of pooled data to date shows that hearing preservation rates achieved by microsurgery in patients with tumors less than $1.5 \mathrm{~cm}$ in size are similar to those observed in the literature for SRS. Nonetheless, the results of these systematic reviews are based largely on Level 3 or 4 evidence and should be interpreted cautiously. The prospective comparative studies that compare the results of small VSs treated with SRS or microsurgery at a single institution provide probably the best available evidence from 
which conclusions can be drawn (Table 4), suggesting that SRS is the best management strategy, considering CN VII and VIII preservation rates and postprocedural quality of life. Moreover, similar results have been demonstrated by other retrospective studies. ${ }^{46,63,78,79,84,113}$ That being said, the results of a prospective nonrandomized comparative study (Level 2 evidence) are contrary to the aforementioned one. ${ }^{24}$ At almost 3 years' follow-up, there was no statistically significant difference across the various health dimensions pertaining to quality of life (SF-36 questionnaire) for the observation, SRS, and microsurgery groups. Similar results were reported in a multicenter cross-sectional study with a maximum follow-up of no more than 5 years. ${ }^{14}$ One must remember that long-term follow-up data ( $>10$ years) in an SRS group are still not widely available.

Koos et al. ${ }^{50}$ reported remarkable results in their group of patients with small VSs treated by microsurgery. Good hearing (using the 50/50 rule) was maintained in $100 \%$ of patients with Koos Stage 1 tumors and in $87 \%$ of patients with Koos Stage 2 tumors. Of patients presenting initially with House-Brackmann Grade 1 or 2 facial nerve function, $88 \%$ had House-Brackmann Grade 1 function 18 months postoperatively. These results have not been widely reproducible.

To summarize, if a young or middle-aged patient presents with serviceable hearing loss, following a waitand-scan strategy is unlikely to do any good with respect to the ongoing active tumorigenesis and the patient's hearing status. Considering the chances of stabilizing or improving hearing status, freedom from future treatment at 10 years' follow-up, and the quality of treatment, the literature suggests that such patients may benefit the most from SRS. Since data for 20-year follow-up are not widely available for SRS (as opposed to microsurgery), one would have to clearly inform patients of the potential long-term failures that have not yet been well described.

\section{Hypothetical Case 3}

This patient is 40 -year-old woman with a small VS $(<25$ $\mathrm{mm}$ ) and a serviceable hearing level. The patient works as a newscaster or a professional model, and therefore, apart from hearing preservation, her primary concern is to maximize the chances of preservation of normal facial movement.

Facial Nerve Outcomes After Microsurgery. A recent systematic review addressing facial nerve outcomes after microsurgery examined data from 79 articles pertaining to a total of 11,873 patients. ${ }^{102}$ Although the inclusion criteria were not specific for tumor size, the authors were able to compare the facial nerve preservation rates in 2 subgroups: studies with a mean tumor size $<20 \mathrm{~mm}$ $(90 \%)$ and studies with a mean tumor size $>20 \mathrm{~mm}(67 \%)$. A previous meta-analysis done in 2003 yielded similar results. ${ }^{113}$ In the studies representing Class II evidence for treatment of small VSs, the postoperative rate of facial nerve preservation ranged from $53 \%$ to $76 \%$ (Table 4), remarkably worse than the results reported in systematic reviews that largely represent data from retrospective case series. ${ }^{102}$ It is evident that smaller VSs treated with microsurgery have better hearing and facial nerve preservation rate than larger VSs (Fig. 2). Class II or higher evidence for intracanalicular VS managed through microsurgery is lacking. Recently, Noudel et al. ${ }^{70}$ conducted a systematic review that included 35 studies of microsurgical resection of intracanalicular VS. They reported that the average hearing preservation rate (AAO-HNS Classes $\mathrm{A}$ and $\mathrm{B}$ or GRC I and II) for intracanalicular VS was $58 \%$ with a retrosigmoid approach and $62 \%$ with a middle fossa approach. Interestingly, facial nerve preservation (HouseBrackmann Grade 1 or 2) was as high as $91 \%$ in the retrosigmoid approach group as compared with $77 \%$ in the middle fossa approach group, although the difference was not statistically significant $(\mathrm{p}>0.05)$.

Facial Nerve Outcomes After SRS. Recently, Yang et al. ${ }^{116}$ quantified the existing data to evaluate facial nerve preservation after SRS, and the results correlated with what one would intuitively expect. The authors reported an overall facial nerve preservation rate of $96.2 \%$; for the population with tumors of less than $1.5 \mathrm{~cm}^{3}$ in volume, the rate was $99.5 \%$. They also found that reduction of the radiation dose to less than 13 Gy was associated with significant improvement in facial nerve preservation rates. In all but one of the comparative prospective studies, facial nerve preservation rates were much higher in the SRS treatment groups than in the microsurgery groups. The one exception was the study by Di Maio and Akagami, ${ }^{24}$ who reported no statistically significant difference in the incidence of facial weakness between the microsurgery and SRS groups.

To summarize, in a young or middle-aged patient who presents with serviceable hearing and in whom preservation of facial function is crucial (for example, in someone who works as a newscaster or professional model), the literature suggests the superiority of SRS over observation or microsurgery.

\section{Hypothetical Case 4}

This patient is a 40-year-old man with a small VS $(<25$ $\mathrm{mm})$ and with a nonserviceable hearing level. He wants the best chance to stabilize or restore hearing function and emphasizes his desire to choose an intervention that will provide him with best quality of life.

Currently the data in the literature are equivocal with respect to the choice between microsurgery and SRS for patients with small VSs who present with a nonserviceable hearing level. In patients who have already lost serviceable hearing it is worthwhile to consider tumor control and treatment-related morbidity factors that influence quality of life. In patients presenting with profound hearing loss, comparative prospective studies have not found any statistically significant difference among those undergoing SRS and those undergoing microsurgery in terms of quality of life. ${ }^{36}$ Whitmore et al. ${ }^{111}$ recently reported the results of a comprehensive quantitative, statistically driven study designed to determine which treatment modality yields the best quality of life at 5- and 10-year follow-up in patients with VSs smaller than $25 \mathrm{~mm}$ in diameter who present with some residual hearing. Even though the study was limited by the assumptions the authors had to make to come up with the best possible comparative model, it provided useful insights into treatment-related morbidity 

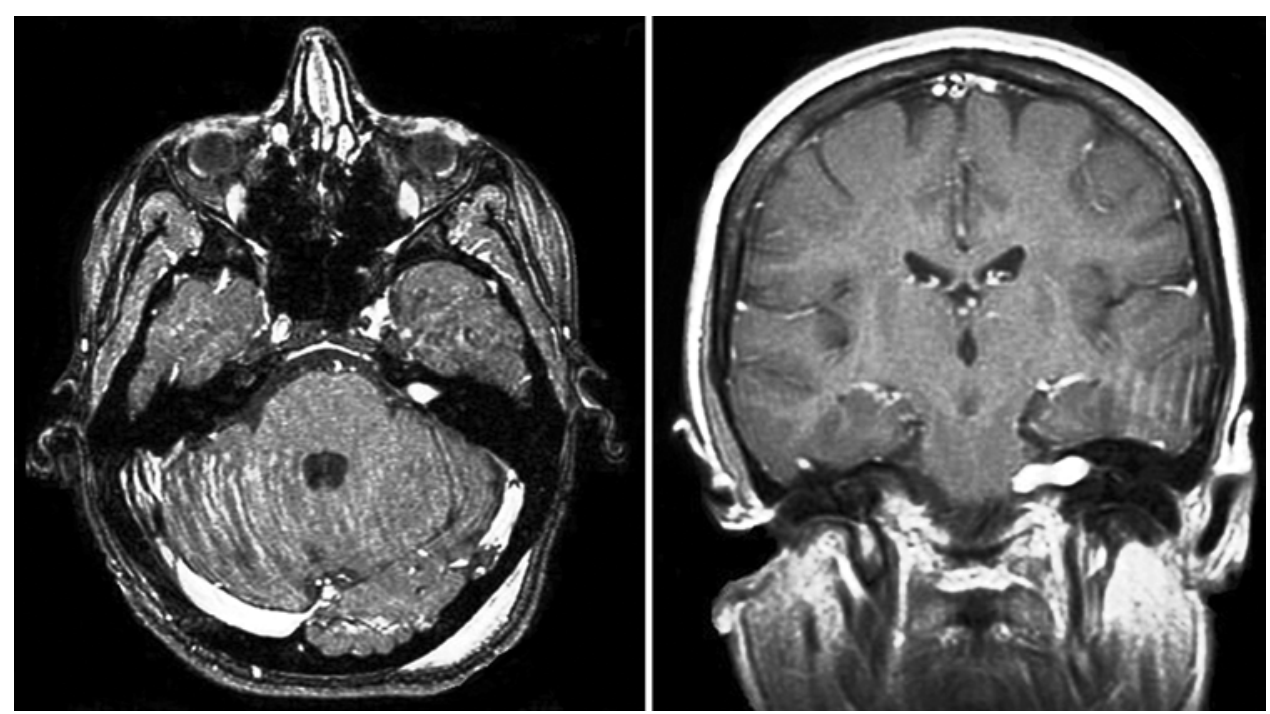

Fig. 2. Contrast-enhanced T1-weighted MR images demonstrating small VSs with diameters of $1 \mathrm{~cm}$ (left) and $2 \mathrm{~cm}$ (right). Systematic review of mostly Class 3 evidence suggests that the chances of facial nerve preservation after microsurgery is significantly higher in tumors $1.5 \mathrm{~cm}$ or less in diameter than in those with a diameter of more than $1.5 \mathrm{~cm}$.

parameters and their influence on postoperative quality of life. The authors concluded that at 5 years posttreatment, patients who underwent radiosurgery had a better quality of life than those treated with either microsurgery or managed with observation. At 10 years, quality of life in both the radiosurgery and microsurgery groups was significantly better than in the observation group, but there was no statistically significant difference in the quality of life between the SRS and microsurgery groups. The authors also found that hearing loss had a greater overall negative impact on quality of life than other morbidities, including facial weakness and numbness. This finding was also documented by a previous prospective study ${ }^{24}$ (Level 2 evidence). Some studies have also shown that disabling imbalance has the maximum negative impact among complications involving CN VII and VIII (that is, audiofacial complications, including facial nerve palsy and hearing loss) and nonaudiofacial complications. In these studies, microsurgical resection was associated with the alleviation of the disability and improvement in quality of life for the majority of patients. ${ }^{55}$

Based on the current review of the literature, in patients presenting with a nonserviceable hearing level, SRS does not seem to provide any additional advantage over microsurgery. There is no significant difference in the quality of life; incidence of nonaudiofacial complications, including tinnitus, vertigo, and unsteadiness; and tumor control among the 2 treatment modalities, although there is a trend toward better results in patients complaining of imbalance in the microsurgery group. Some authors have reported comparable results of facial nerve preservation with microsurgical excision (especially for tumors less than $1.5 \mathrm{~cm}$ in diameter). ${ }^{24,87,102}$ Certainly, surgical experience is an important factor that needs to be taken into account when analyzing and comparing outcomes of surgical treatment of small VS. At the hands of some experienced surgeons, facial nerve outcomes are excellent in patients treated for small VS, and it is worthwhile to consider microsurgery as a safe alternative in patients with nonserviceable hearing. ${ }^{24,87,102}$

Also, in a patient whose hearing status is out of the equation, the small but real risk of radiation-induced malignancy may be considered (especially if the patient is young). ${ }^{23,90}$ Additionally, Di Maio et al. ${ }^{24}$ showed in their prospective study that patients in the observation and radiation groups may have a greater psychological burden associated with harboring a tumor than those treated with surgery. Therefore, when improvement in hearing status is unlikely, microsurgery is certainly a valid treatment option.

\section{Hypothetical Case 5}

This patient is a 65-year-old man (or other adult with significant comorbidities), with a small VS $(<25 \mathrm{~mm})$ and serviceable hearing loss. He seeks advice regarding the best possible way to stabilize the hearing loss and maintain an optimal quality of life for the coming years.

There seems to be a general consensus on the treatment strategy for these patients in the literature. If the patients' symptoms are minimal, the support for observation with serial imaging is immense. There is a great chance in this age group that active treatment may not be necessary. ${ }^{39,110}$ Furthermore, in the studies that address long-term follow-up for conservatively managed cases, patients 65 years or older represent a substantial percentage in the cohort. ${ }^{12,39}$ For patients in this age group who are symptomatic or in whom rapid tumor growth $(>2.5$ $\mathrm{mm} /$ year) is documented, SRS seems to provide the best audiofacial outcomes and postoperative quality of life (Table 4). The nonaudiofacial postoperative morbidities, such as dysequilibrium, vertigo, and tinnitus, can usually be managed by appropriate rehabilitative services.

\section{Special Considerations}

Sudden Hearing Loss in Small VS

The percentage of cases in which patients present 


\section{J. D. Thakur et al.}

with sudden hearing loss is relatively low $(0.8 \%-3.7 \%) .^{15}$ The chances of restoration of sudden hearing loss in VS patient through radiosurgery are not well documented. Most of the authors studying sudden hearing loss describe their treatment protocol as a combination of microsurgery and medical management with corticosteroid agents and vitamin $\mathrm{B}_{12} \cdot{ }^{32,42,88}$ Friedman et al. ${ }^{32}$ reported measurable hearing preservation after microsurgery in $73 \%$ of their patients with VSs less than $2 \mathrm{~cm}$ in diameter who presented with sudden hearing loss. Even though there remains a small chance of measurable-to-complete recovery with just observation or with medical therapy alone, microsurgery may provide the best chance of stabilizing or improving hearing in patients with small VSs presenting with sudden hearing loss. ${ }^{11,32,42,65,88}$

\section{Cystic Small VS}

Cystic lesions account for approximately 4\%-15\% of all VS cases. ${ }^{22,76}$ They are characterized by rapid growth and therefore may result in a shorter duration of symptoms related to the vestibulocochlear and facial nerves and may also be seen in certain cases of small VS. Management of small VS with a cystic component is contentious. ${ }^{10,16,}$ 17,22,33,74,92,94,107 There is a severe lack of comparative data (even Level 3 or 4 evidence) to support the superiority of surgery or SRS or radiotherapy as a treatment strategy. Treatment of these lesions by means of either microsurgery or SRS is challenging and fraught with risks. Enlargement of the cyst following radiation, even after several years, has been noted to occur, and in some cases emergent surgical decompression may be required to avoid permanent cranial neuropathy. ${ }^{22,35,74,92}$ Results of surgery, however, are also known to be unfavorable for cystic VS, and surgical treatment is associated with higher rates of morbidity..$^{10,17,33,94,107}$ At this point, the data in support of SRS or radiation therapy for treatment of cystic VS are too scant to even consider these treatments as reasonable alternatives to surgery. ${ }^{92}$ That being said, SRS and radiotherapy as well as surgery would have to be evaluated with better study designs and longer follow-up.

\section{Syndrome-Associated Small VSs}

Apart from being sporadic, VSs are known to develop in patients with neurofibromatosis Type 2. They may be unilateral or bilateral. Various studies have highlighted their unpredictable and unique natural history, growth patterns, and treatment response. ${ }^{1,25,29}$ Discussion of neurofibromatosis Type 2 is beyond the scope of this article.

\section{Limitations of this Review}

Comprehensive systematic analyses currently existing in the literature have a restricted clinical applicability due to the numerous inconsistencies, selection biases and lower level of evidence. For this reason, this review also has its limitations in suggesting a standard algorithm based on the limited higher form of evidence, even though every effort was made to customize answers to patient-specific requirements based on the level of evidence existing in the literature.

\section{Conclusions}

Even after more than 100 years since the first VS surgery, the controversy in treatment strategy remains. More large-scale prospective randomized trials may help us to better understand the "best" therapeutic option for certain patient scenarios. To achieve statistical significance for comparing outcomes for observation, radiosurgery and microsurgery for small vestibular schwannomas, a cohort of over 900-1000 patients followed for over 10 years is required. The logistics of obtaining the required sample size is challenging. Due to the paucity of high-level evidence to compare the treatment groups, proponents of each option will presumably stick with their current preference. We have attempted to extrapolate from the literature to specific patient scenarios. The existing evidence suggests that the treatment of small VS should always be tailored to the individual patient rather than being a generalized treatment protocol. We hope that our case-specific review may serve as a guide for neurosurgeons, neuro-otologists, and radiation oncologists treating this ever-increasing patient population and may encourage focused prospective randomized trials.

\section{Disclosure}

The authors report no conflict of interest concerning the materials or methods used in this study or the findings specified in this paper.

Author contributions to the study and manuscript preparation include the following. Conception and design: Guthikonda, Thakur, Banerjee, Gardner, Nanda. Acquisition of data: Thakur, Banerjee, Khan. Analysis and interpretation of data: Thakur, Banerjee, Sonig, Shorter. Drafting the article: Thakur, Banerjee, Khan, Sonig. Critically revising the article: Guthikonda, Khan, Sonig, Shorter, Gardner. Reviewed submitted version of manuscript: Guthikonda. Approved the final version of the manuscript on behalf of all authors: Guthikonda. Administrative/technical/material support: Gardner, Nanda.

\section{References}

1. Aghi M, Kluwe L, Webster MT, Jacoby LB, Barker FG II, Ojemann RG, et al: Unilateral vestibular schwannoma with other neurofibromatosis type 2-related tumors: clinical and molecular study of a unique phenotype. J Neurosurg 104:201-207, 2006

2. Agrawal Y, Clark JH, Limb CJ, Niparko JK, Francis HW: Predictors of vestibular schwannoma growth and clinical implications. Otol Neurotol 31:807-812, 2010

3. Ahn MS, Jackler RK, Lustig LR: The early history of the neurofibromatosis. Evolution of the concept of neurofibromatosis type 2. Arch Otolaryngol Head Neck Surg 122:1240-1249, 1996

4. Arthurs BJ, Fairbanks RK, Demakas JJ, Lamoreaux WT, Giddings NA, Mackay AR, et al: A review of treatment modalities for vestibular schwannoma. Neurosurg Rev 34:265-279, 2011

5. Artz JCJM, Timmer FCA, Mulder JJS, Cremers CWRJ, Graamans K: Predictors of future growth of sporadic vestibular schwannomas obtained by history and radiologic assessment of the tumor. Eur Arch Otorhinolaryngol 266:641-646, 2009

6. Arvold ND, Guha N, Wang D, Matli M, Deen DF, Warren RS, et al: Hypoxia-induced radioresistance is independent of hypoxia-inducible factor-1 A in vitro. Int J Radiat Oncol Biol Phys 62:207-212, 2005

7. Badie B, Pyle GM, Nguyen PH, Hadar EJ: Elevation of inter- 
nal auditory canal pressure by vestibular schwannomas. Otol Neurotol 22:696-700, 2001

8. Ballance C: Some Points in the Surgery of the Brain and Its Membranes, ed 2. London: Macmillan, 1908

9. Battaglia A, Mastrodimos B, Cueva R: Comparison of growth patterns of acoustic neuromas with and without radiosurgery. Otol Neurotol 27:705-712, 2006

10. Benech F, Perez R, Fontanella MM, Morra B, Albera R, Ducati A: Cystic versus solid vestibular schwannomas: a series of 80 grade III-IV patients. Neurosurg Rev 28:209-213, 2005

11. Berg HM, Cohen NL, Hammerschlag PE, Waltzman SB: Acoustic neuroma presenting as sudden hearing loss with recovery. Otolaryngol Head Neck Surg 94:15-22, 1986

12. Bozorg Grayeli A, Kalamarides M, Ferrary E, Bouccara D, El Gharem H, Rey A, et al: Conservative management versus surgery for small vestibular schwannomas. Acta Otolaryngol 125:1063-1068, 2005

13. Breivik CN, Varughese JK, Wentzel-Larsen T, Vassbotn F, Lund-Johansen M: Conservative management of vestibular schwannoma-a prospective cohort study: treatment, symptoms, and quality of life. Neurosurgery 70:1072-1080, 2012

14. Brooker JE, Fletcher JM, Dally MJ, Briggs RJS, Cousins VC, Smee RI, et al: Quality of life among acoustic neuroma patients managed by microsurgery, radiation, or observation. Otol Neurotol 31:977-984, 2010

15. Chaimoff M, Nageris BI, Sulkes J, Spitzer T, Kalmanowitz M: Sudden hearing loss as a presenting symptom of acoustic neuroma. Am J Otolaryngol 20:157-160, 1999

16. Charabi S, Klinken L, Tos M, Thomsen J: Histopathology and growth pattern of cystic acoustic neuromas. Laryngoscope 104:1348-1352, 1994

17. Charabi S, Tos M, Børgesen SE, Thomsen J: Cystic acoustic neuromas. Results of translabyrinthine surgery. Arch Otolaryngol Head Neck Surg 120:1333-1338, 1994

18. Cheng S, Naidoo Y, da Cruz M, Dexter M: Quality of life in postoperative vestibular schwannoma patients. Laryngoscope 119:2252-2257, 2009

19. Chopra R, Kondziolka D, Niranjan A, Lunsford LD, Flickinger JC: Long-term follow-up of acoustic schwannoma radiosurgery with marginal tumor doses of 12 to 13 Gy. Int J Radiat Oncol Biol Phys 68:845-851, 2007

20. Ciuman RR: The efferent system or olivocochlear function bundle-fine regulator and protector of hearing perception. Int J Biomed Sci 6:276-288, 2010

21. Coelho DH, Roland JT Jr, Rush SA, Narayana A, St Clair E, Chung W, et al: Small vestibular schwannomas with no hearing: comparison of functional outcomes in stereotactic radiosurgery and microsurgery. Laryngoscope 118:1909-1916, 2008

22. de Ipolyi AR, Yang I, Buckley A, Barbaro NM, Cheung SW, Parsa AT: Fluctuating response of a cystic vestibular schwannoma to radiosurgery: case report. Neurosurgery 62:E11641165,2008

23. Demetriades AK, Saunders N, Rose P, Fisher C, Rowe J, Tranter R, et al: Malignant transformation of acoustic neuroma/vestibular schwannoma 10 years after gamma knife stereotactic radiosurgery. Skull Base 20:381-387, 2010

24. Di Maio S, Akagami R: Prospective comparison of quality of life before and after observation, radiation, or surgery for vestibular schwannomas. Clinical article. J Neurosurg 111: 855-862, 2009

25. Dirks MS, Butman JA, Kim HJ, Wu T, Morgan K, Tran AP, et al: Long-term natural history of neurofibromatosis Type 2-associated intracranial tumors. Clinical article. J Neurosurg 117:109-117, 2012

26. Eckermeier L, Pirsig W, Mueller D: Histopathology of 30 nonoperated acoustic schwannomas. Arch Otorhinolaryngol 222: $1-9,1979$

27. Ferri GG, Modugno GC, Calbucci F, Ceroni AR, Pirodda A: Hearing loss in vestibular schwannomas: analysis of cochlear function by means of distortion-product otoacoustic emissions. Auris Nasus Larynx 36:644-648, 2009

28. Ferri GG, Modugno GC, Pirodda A, Fioravanti A, Calbucci F, Ceroni AR: Conservative management of vestibular schwannomas: an effective strategy. Laryngoscope 118:951-957, 2008

29. Fisher LM, Doherty JK, Lev MH, Slattery WH: Concordance of bilateral vestibular schwannoma growth and hearing changes in neurofibromatosis 2: neurofibromatosis 2 natural history consortium. Otol Neurotol 30:835-841, 2009

30. Flickinger JC, Kondziolka D, Niranjan A, Maitz A, Voynov G, Lunsford LD: Acoustic neuroma radiosurgery with marginal tumor doses of 12 to 13 Gy. Int J Radiat Oncol Biol Phys 60: 225-230, 2004

31. Fraenkel J, Hunt JR, Woolsey G, Elsberg CA: I. Contribution to the surgery of neurofibroma of the acoustic nerve: with remarks on the surgical procedure. Ann Surg 40:293-319, 1904

32. Friedman RA, Kesser BW, Slattery WH III, Brackmann DE, Hitselberger WE: Hearing preservation in patients with vestibular schwannomas with sudden sensorineural hearing loss. Otolaryngol Head Neck Surg 125:544-551, 2001

33. Fundová P, Charabi S, Tos M, Thomsen J: Cystic vestibular schwannoma: surgical outcome. J Laryngol Otol 114:935939, 2000

34. Gal TJ, Shinn J, Huang B: Current epidemiology and management trends in acoustic neuroma. Otolaryngol Head Neck Surg 142:677-681, 2010

35. Ganslandt O, Fahrig A, Strauss C: Hemorrhage into cystic vestibular schwannoma following stereotactic radiation therapy. Zentralbl Neurochir 69:204-206, 2008

36. Gouveris HT, Mann WJ: Quality of life in sporadic vestibular schwannoma: a review. ORL J Otorhinolaryngol Relat Spec 72:69-74, 2010

37. Gouveris HT, Victor A, Mann WJ: Cochlear origin of early hearing loss in vestibular schwannoma. Laryngoscope 117: 680-683, 2007

38. Graamans K, Van Dijk JE, Janssen LW: Hearing deterioration in patients with a non-growing vestibular schwannoma. Acta Otolaryngol 123:51-54, 2003

39. Hajioff D, Raut VV, Walsh RM, Bath AP, Bance ML, Guha A, et al: Conservative management of vestibular schwannomas: third review of a 10 -year prospective study. Clin Otolaryngol 33:255-259, 2008

40. Hasegawa T, Fujitani S, Katsumata S, Kida Y, Yoshimoto M, Koike J: Stereotactic radiosurgery for vestibular schwannomas: analysis of 317 patients followed more than 5 years. Neurosurgery 57:257-265, 2005

41. Herwadker A, Vokurka EA, Evans DGR, Ramsden RT, Jackson A: Size and growth rate of sporadic vestibular schwannoma: predictive value of information available at presentation. Otol Neurotol 26:86-92, 2005

42. Inoue Y, Kanzaki J, Ogawa K: Vestibular schwannoma presenting as sudden deafness. J Laryngol Otol 114:589-592, 2000

43. Iwai Y, Yamanaka K, Yamagata K, Yasui T: Surgery after radiosurgery for acoustic neuromas: surgical strategy and histological findings. Neurosurgery 60:ONS75-ONS82, 2007

44. Jacob A, Robinson LL Jr, Bortman JS, Yu L, Dodson EE, Welling DB: Nerve of origin, tumor size, hearing preservation, and facial nerve outcomes in 359 vestibular schwannoma resections at a tertiary care academic center. Laryngoscope 117:2087-2092, 2007

45. Kano H, Kondziolka D, Khan A, Flickinger JC, Lunsford LD: Predictors of hearing preservation after stereotactic radiosurgery for acoustic neuroma. Clinical article. J Neurosurg 111: 863-873, 2009

46. Karpinos M, Teh BS, Zeck O, Carpenter LS, Phan C, Mai WY, et al: Treatment of acoustic neuroma: stereotactic radiosurgery vs. microsurgery. Int J Radiat Oncol Biol Phys 54: 1410-1421, 2002

47. Kaylie DM, Horgan MJ, Delashaw JB, McMenomey SO: A 
meta-analysis comparing outcomes of microsurgery and gamma knife radiosurgery. Laryngoscope 110:1850-1856, 2000

48. Komatsuzaki A, Tsunoda A: Nerve origin of the acoustic neuroma. J Laryngol Otol 115:376-379, 2001

49. Kondziolka D, Nathoo N, Flickinger JC, Niranjan A, Maitz $\mathrm{AH}$, Lunsford LD: Long-term results after radiosurgery for benign intracranial tumors. Neurosurgery 53:815-822, 2003

50. Koos WT, Day JD, Matula C, Levy DI: Neurotopographic considerations in the microsurgical treatment of small acoustic neurinomas. J Neurosurg 88:506-512, 1998

51. Lapsiwala SB, Pyle GM, Kaemmerle AW, Sasse FJ, Badie B: Correlation between auditory function and internal auditory canal pressure in patients with vestibular schwannomas. J Neurosurg 96:872-876, 2002

52. Lasak JM, Klish D, Kryzer TC, Hearn C, Gorecki JP, Rine GP: Gamma knife radiosurgery for vestibular schwannoma: early hearing outcomes and evaluation of the cochlear dose. Otol Neurotol 29:1179-1186, 2008

53. Lee F, Linthicum F Jr, Hung G: Proliferation potential in recurrent acoustic schwannoma following gamma knife radiosurgery versus microsurgery. Laryngoscope 112:948-950, 2002

54. Linskey ME: Stereotactic radiosurgery versus stereotactic radiotherapy for patients with vestibular schwannoma: a Leksell Gamma Knife Society 2000 debate. J Neurosurg 93 (Suppl 3):90-95, 2000

55. Lloyd SKW, Kasbekar AV, Baguley DM, Moffat DA: Audiovestibular factors influencing quality of life in patients with conservatively managed sporadic vestibular schwannoma. Otol Neurotol 31:968-976, 2010

56. Lobato-Polo J, Kondziolka D, Zorro O, Kano H, Flickinger JC, Lunsford LD: Gamma knife radiosurgery in younger patients with vestibular schwannomas. Neurosurgery 65:294-301, 2009

57. Mahmud MR, Khan AM, Nadol JB Jr: Histopathology of the inner ear in unoperated acoustic neuroma. Ann Otol Rhinol Laryngol 112:979-986, 2003

58. Massager N, Nissim O, Delbrouck C, Delpierre I, Devriendt $\mathrm{D}$, Desmedt F, et al: Irradiation of cochlear structures during vestibular schwannoma radiosurgery and associated hearing outcome. J Neurosurg 107:733-739, 2007

59. Massick DD, Welling DB, Dodson EE, Scholfield M, Nagaraja $\mathrm{HN}$, Schmalbrock $\mathrm{P}$, et al: Tumor growth and audiometric change in vestibular schwannomas managed conservatively. Laryngoscope 110:1843-1849, 2000

60. Moffat DA, Baguley DM, von Blumenthal H, Irving RM, Hardy DG: Sudden deafness in vestibular schwannoma. J Laryngol Otol 108:116-119, 1994

61. Morrison D: Management of patients with acoustic neuromas: a Markov decision analysis. Laryngoscope 120:783-790, 2010

62. Myrseth E, Møller P, Pedersen PH, Lund-Johansen M: Vestibular schwannoma: surgery or gamma knife radiosurgery? A prospective, nonrandomized study. Neurosurgery 64:654663,2009

63. Myrseth E, Møller P, Pedersen PH, Vassbotn FS, WentzelLarsen T, Lund-Johansen M: Vestibular schwannomas: clinical results and quality of life after microsurgery or gamma knife radiosurgery. Neurosurgery 56:927-935, 2005

64. Nagano O, Serizawa T, Higuchi Y, Matsuda S, Sato M, Yamakami I, et al: Tumor shrinkage of vestibular schwannomas after Gamma Knife surgery: results after more than 5 years of follow-up. J Neurosurg 113 (Suppl):122-127, 2010

65. Nageris BI, Popovtzer A: Acoustic neuroma in patients with completely resolved sudden hearing loss. Ann Otol Rhinol Laryngol 112:395-397, 2003

66. Nakamura H, Jokura H, Takahashi K, Boku N, Akabane A, Yoshimoto T: Serial follow-up MR imaging after gamma knife radiosurgery for vestibular schwannoma. AJNR Am J Neuroradiol 21:1540-1546, 2000

67. Neely JG: Gross and microscopic anatomy of the eighth cranial nerve in relationship to the solitary schwannoma. Laryngoscope 91:1512-1531, 1981
68. Nikolopoulos TP, Fortnum H, O’Donoghue G, Baguley D: Acoustic neuroma growth: a systematic review of the evidence. Otol Neurotol 31:478-485, 2010

69. Niranjan A, Mathieu D, Flickinger JC, Kondziolka D, Lunsford LD: Hearing preservation after intracanalicular vestibular schwannoma radiosurgery. Neurosurgery 63:1054-1063, 2008

70. Noudel R, Gomis P, Duntze J, Marnet D, Bazin A, Roche PH: Hearing preservation and facial nerve function after microsurgery for intracanalicular vestibular schwannomas: comparison of middle fossa and retrosigmoid approaches. Acta Neurochir (Wien) 151:935-945, 2009

71. O-Uchi T, Kanzaki J, Ogata A, Inoue T, Mashino H, Yoshihara $\mathrm{S}$, et al: Pathophysiology of hearing impairment in acoustic neuroma with profound deafness: analysis by evoked otoacoustic emission and promontory stimulation test. Acta Otolaryngol Suppl 514:95-100, 1994

72. Odabasi AO, Telischi FF, Gomez-Marin O, Stagner B, Martin $\mathrm{G}$ : Effect of acoustic tumor extension into the internal auditory canal on distortion-product otoacoustic emissions. Ann Otol Rhinol Laryngol 111:912-915, 2002

73. Patuzzi R, Rajan R: Additivity of threshold elevations produced by disruption of outer hair cell function. Hear Res 60: 165-177, 1992

74. Pendl G, Ganz JC, Kitz K, Eustacchio S: Acoustic neurinomas with macrocysts treated with Gamma Knife radiosurgery. Stereotact Funct Neurosurg 66 (Suppl 1):103-111, 1996

75. Pennings RJE, Morris DP, Clarke L, Allen S, Walling S, Bance ML: Natural history of hearing deterioration in intracanalicular vestibular schwannoma. Neurosurgery 68:68-77, 2011

76. Piccirillo E, Wiet MR, Flanagan S, Dispenza F, Giannuzzi A, Mancini F, et al: Cystic vestibular schwannoma: classification, management, and facial nerve outcomes. Otol Neurotol 30:826-834, 2009

77. Pollock BE: Management of vestibular schwannomas that enlarge after stereotactic radiosurgery: treatment recommendations based on a 15 year experience. Neurosurgery 58:241248, 2006

78. Pollock BE, Driscoll CLW, Foote RL, Link MJ, Gorman DA, Bauch CD, et al: Patient outcomes after vestibular schwannoma management: a prospective comparison of microsurgical resection and stereotactic radiosurgery. Neurosurgery 59:77-85, 2006

79. Pollock BE, Lunsford LD, Kondziolka D, Flickinger JC, Bissonette DJ, Kelsey SF, et al: Outcome analysis of acoustic neuroma management: a comparison of microsurgery and stereotactic radiosurgery. Neurosurgery 36:215-229, 1995

80. Prasad D, Steiner M, Steiner L: Gamma surgery for vestibular schwannoma. J Neurosurg 92:745-759, 2000

81. Prasher DK, Tun T, Brookes GB, Luxon LM: Mechanisms of hearing loss in acoustic neuroma: an otoacoustic emission study. Acta Otolaryngol 115:375-381, 1995

82. Raut VV, Walsh RM, Bath AP, Bance ML, Guha A, Tator CH, et al: Conservative management of vestibular schwannomas second review of a prospective longitudinal study. Clin Otolaryngol Allied Sci 29:505-514, 2004

83. Régis J, Carron R, Park MC, Soumare O, Delsanti C, Thomassin JM, et al: Wait-and-see strategy compared with proactive Gamma Knife surgery in patients with intracanalicular vestibular schwannomas. J Neurosurg 113 Suppl:105-111, 2010

84. Régis J, Pellet W, Delsanti C, Dufour H, Roche PH, Thomassin JM, et al: Functional outcome after gamma knife surgery or microsurgery for vestibular schwannomas. J Neurosurg 97: 1091-1100, 2002

85. Régis J, Roche PH, Delsanti C, Thomassin JM, Ouaknine M, Gabert K, et al: Modern management of vestibular schwannomas. Prog Neurol Surg 20:129-141, 2007

86. Rosenberg SI: Natural history of acoustic neuromas. Laryngoscope 110:497-508, 2000 
87. Samii M, Gerganov V, Samii A: Improved preservation of hearing and facial nerve function in vestibular schwannoma surgery via the retrosigmoid approach in a series of 200 patients. J Neurosurg 105:527-535, 2006

88. Sauvaget E, Kici S, Kania R, Herman P, Tran Ba Huy P: Sudden sensorineural hearing loss as a revealing symptom of vestibular schwannoma. Acta Otolaryngol 125:592-595, 2005

89. Selesnick SH, Johnson G: Radiologic surveillance of acoustic neuromas. Am J Otol 19:846-849, 1998

90. Shin M, Ueki K, Kurita H, Kirino T: Malignant transformation of a vestibular schwannoma after gamma knife radiosurgery. Lancet 360:309-310, 2002

91. Shin YJ, Lapeyre-Mestre M, Gafsi I, Cognard C, Deguine O, Tremoulet M, et al: Neurotological complications after radiosurgery versus conservative management in acoustic neuromas: a systematic review-based study. Acta Otolaryngol 123:59-64, 2003

92. Shirato H, Sakamoto T, Takeichi N, Aoyama H, Suzuki K, Kagei K, et al: Fractionated stereotactic radiotherapy for vestibular schwannoma (VS): comparison between cystictype and solid-type VS. Int J Radiat Oncol Biol Phys 48: 1395-1401, 2000

93. Silverstein H: Inner ear fluid proteins in acoustic neuroma, Menière's disease and otosclerosis. Ann Otol Rhinol Laryngol 80:27-35, 1971

94. Sinha S, Sharma BS: Cystic acoustic neuromas: surgical outcome in a series of 58 patients. J Clin Neurosci 15:511-515, 2008

95. Smouha EE, Yoo M, Mohr K, Davis RP: Conservative management of acoustic neuroma: a meta-analysis and proposed treatment algorithm. Laryngoscope 115:450-454, 2005

96. Stangerup SE, Caye-Thomasen P, Tos M, Thomsen J: Change in hearing during 'wait and scan' management of patients with vestibular schwannoma. J Laryngol Otol 122:673-681, 2008

97. Stangerup SE, Thomsen J, Tos M, Cayé-Thomasen P: Longterm hearing preservation in vestibular schwannoma. Otol Neurotol 31:271-275, 2010

98. Sughrue ME, Kane AJ, Kaur R, Barry JJ, Rutkowski MJ, Pitts LH, et al: A prospective study of hearing preservation in untreated vestibular schwannomas. Clinical article. J Neurosurg 114:381-385, 2011

99. Sughrue ME, Kaur R, Kane AJ, Rutkowski MJ, Yang I, Pitts LH, et al: Intratumoral hemorrhage and fibrosis in vestibular schwannoma: a possible mechanism for hearing loss. Clinical article. J Neurosurg 114:386-393, 2011

100. Sughrue ME, Yang I, Aranda D, Kane AJ, Parsa AT: Hearing preservation rates after microsurgical resection of vestibular schwannoma. J Clin Neurosci 17:1126-1129, 2010

101. Sughrue ME, Yang I, Aranda D, Lobo K, Pitts LH, Cheung SW, et al: The natural history of untreated sporadic vestibular schwannomas: a comprehensive review of hearing outcomes. Clinical article. J Neurosurg 112:163-167, 2010

102. Sughrue ME, Yang I, Rutkowski MJ, Aranda D, Parsa AT: Preservation of facial nerve function after resection of vestibular schwannoma. Br J Neurosurg 24:666-671, 2010

103. Tamura M, Carron R, Yomo S, Arkha Y, Muraciolle X, Porcheron D, et al: Hearing preservation after gamma knife radiosurgery for vestibular schwannomas presenting with high-level hearing. Neurosurgery 64:289-296, 2009

104. van de Langenberg R, de Bondt BJ, Nelemans PJ, Dohmen AJC, Baumert BG, Stokroos RJ: Predictors of volumetric growth and auditory deterioration in vestibular schwannomas followed in a wait and scan policy. Otol Neurotol 32: 338-344, 2011

105. Vernooij MW, Ikram MA, Tanghe HL, Vincent AJPE,
Hofman A, Krestin GP, et al: Incidental findings on brain MRI in the general population. N Engl J Med 357:18211828,2007

106. Wackym PA, Runge-Samuelson CL, Nash JJ, Poetker DM, Albano K, Bovi J, et al: Gamma knife surgery of vestibular schwannomas: volumetric dosimetry correlations to hearing loss suggest stria vascularis devascularization as the mechanism of early hearing loss. Otol Neurotol 31:1480-1487, 2010

107. Wandong S, Meng L, Xingang L, Yuguang L, Shugan Z, Lei W, et al: Cystic acoustic neuroma. J Clin Neurosci 12: 253-255, 2005

108. Weil RS, Cohen JM, Portarena I, Brada M: Optimal dose of stereotactic radiosurgery for acoustic neuromas: a systematic review. Br J Neurosurg 20: 195-202, 2006

109. Welling DB, Packer MD, Chang LS: Molecular studies of vestibular schwannomas: a review. Curr Opin Otolaryngol Head Neck Surg 15:341-346, 2007

110. Whitehouse K, Foroughi M, Shone G, Hatfield R: Vestibular schwannomas - when should conservative management be reconsidered? Br J Neurosurg 24:185-190, 2010

111. Whitmore RG, Urban C, Church E, Ruckenstein M, Stein SC, Lee JYK: Decision analysis of treatment options for vestibular schwannoma. Clinical article. J Neurosurg 114:400-413, 2011

112. Wowra B, Muacevic A, Jess-Hempen A, Hempel JM, MüllerSchunk S, Tonn JC: Outpatient gamma knife surgery for vestibular schwannoma: definition of the therapeutic profile based on a 10-year experience. J Neurosurg 102 Suppl:114-118, 2005

113. Yamakami I, Uchino Y, Kobayashi E, Yamaura A: Conservative management, gamma-knife radiosurgery, and microsurgery for acoustic neurinomas: a systematic review of outcome and risk of three therapeutic options. Neurol Res 25: 682-690, 2003

114. Yang I, Aranda D, Han SJ, Chennupati S, Sughrue ME, Cheung SW, et al: Hearing preservation after stereotactic radiosurgery for vestibular schwannoma: a systematic review. J Clin Neurosci 16:742-747, 2009

115. Yang I, Sughrue ME, Han SJ, Aranda D, Pitts LH, Cheung SW, et al: A comprehensive analysis of hearing preservation after radiosurgery for vestibular schwannoma. Clinical article. J Neurosurg 112:851-859, 2010

116. Yang I, Sughrue ME, Han SJ, Fang S, Aranda D, Cheung SW, et al: Facial nerve preservation after vestibular schwannoma Gamma Knife radiosurgery. J Neurooncol 93:41-48, 2009

117. Yeung AH, Sughrue ME, Kane AJ, Tihan T, Cheung SW, Parsa AT: Radiobiology of vestibular schwannomas: mechanisms of radioresistance and potential targets for therapeutic sensitization. Neurosurg Focus 27(6):E2, 2009

118. Yoshimoto Y: Systematic review of the natural history of vestibular schwannoma. J Neurosurg 103:59-63, 2005

Manuscript submitted April 27, 2012.

Accepted June 27, 2012.

A portion of the manuscript was presented orally at the 63rd annual meeting of the Southern Neurosurgical Society, Amelia Island, Florida, March 29, 2012.

Please include this information when citing this paper: DOI: 10.3171/2012.6.FOCUS12144.

Address correspondence to: Bharat Guthikonda, M.D., Department of Neurosurgery, Louisiana State University Health Sciences Center-Shreveport, 1501 Kings Highway, Shreveport, Louisiana 71103.email: bguthi@1suhsc.edu. 